\title{
Development and Application of a Pencil-on-Paper Strain Sensor for Pressure Measurement
}

\author{
Nur Shahira Shahripul Azeman, Mohd Norzaidi Mat Nawi
}

Department of Physics, Faculty of Science and Mathematics, Universiti Pendidikan Sultan Idris, Tanjong Malim, Perak 35900, Malaysia

\begin{abstract}
The development and application of a strain sensor using pencil-on-paper is presented in this paper. The use of pencil which contains of graphite create a simple sensing technique that can be used to measure the pressure force. When the pressure force is applied, the beam will deflect and give a change in resistance. A comparison was made using two different types of pencil $2 B$ and $4 B$. $2 B$ pencil was chosen due to the high sensitivity compared to $4 B$ pencil. Sensitivity of the sensor is obtained $0.65 \mathrm{M \Omega} / \mathrm{cm}$ based on the deflection and output resistance. For the application, this sensor has been attached to the latex membrane and observation was made for the pressure measurement based on the applied pressure and different surface area.
\end{abstract}

Keywords: pressure, pencil-on-paper sensor, strain

\section{Introduction}

The uses of pencil-on-paper based sensors has been increasing been used in various types of applications such as detecting chemicals [1,2], tactile sensor [3], strain measurement[4,5], and as a capacitor [6]. It gives advantages in terms of light weight, flexible, portable, easy to dispose and environment-friendly. A pencil-on-paper based sensors can be diversified in many more interesting factors and it is also very useful in a limited natural resource situation and it can provides a new application in art and electronics [4]. This suggests that this pencil-on-paper based sensors provides many benefits to the researchers in order to enhance the sensor design at the same time saving cost. Therefore, the researcher proposed the simple strain sensor by using pencil and paper.

Paper-based sensors are an ever-expanding new innovation worldwide. This innovation is developed to save cost and is made available with easy-to-use materials. Furthermore, this paper-based electronics has gained considerable attention. There are 12 different grades of pencils has been studied from $9 \mathrm{~B}$ to $2 \mathrm{H} \mathrm{[5].} \mathrm{By} \mathrm{using} \mathrm{a} \mathrm{pencil,} \mathrm{researchers} \mathrm{can} \mathrm{make} \mathrm{a}$ simple strain sensor. For this research paper, the pencil-onpaper strain sensor has been developed which focus on the pressure measurement. Two different types of grades including $2 \mathrm{~B}$ and $4 \mathrm{~B}$ are selected because these two types of grades can be easily found in school/university. An experiment for pressure measurement is carried out for pressure in range $0-12 \mathrm{kPa}$ and different surface areas.

\section{Materials and Methods}

The device design is based on the beam structure and the graphite is draw on the section as shown in Figure 1(a). The dimension of the beam is $3 \mathrm{~cm} \mathrm{x} 1 \mathrm{~cm}$ where standard office paper was used to fabricate the sensor. The force is applied on the tip of beam where it will bend or stretch and cause the strain change. The force applied is denoted as $F$, and the total strain is $\varepsilon$.

$$
\varepsilon=\frac{M t}{2 E I}
$$

where $t$ is a thickness of beam, $E$ is a Elastic modulus, and $I$ is a moment of inertia $\left(I=w t^{3} / 12\right)$. The moment $\mathrm{M}$, is approximated

$$
M=F l
$$

By substituting equation (2) and equation moment of inertia into equation (1), the strain for pencil-on-sensor strain sensor is obtained

$$
\varepsilon=\frac{6 F l}{E w t^{2}}
$$

From the equation above, we can conclude that strain of the pencil-on-paper sensor is depends on the force applied, and dimension of beam. For this study, the dimension of beam is fixed and the applied force is varied.

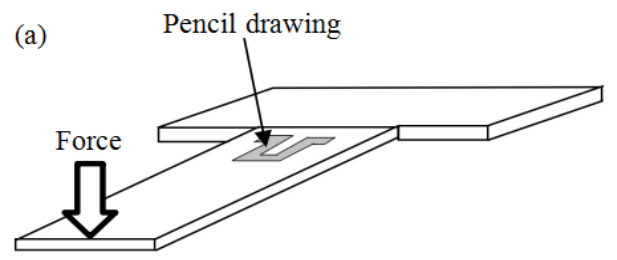

(b)

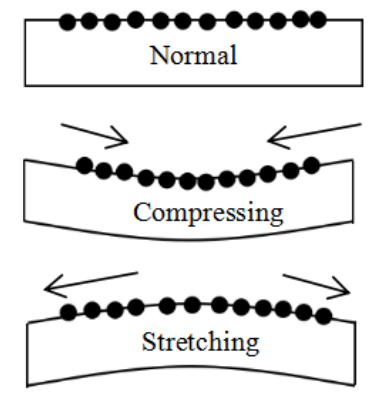

Figure 1: (a) The beam structure of pencil-on-paper device; (b) The sensing principle of pencil-on-paper device

The graphite of pencil is used to convert the strain into

Volume 6 Issue 7, July 2017 www.ijsr.net 


\section{International Journal of Science and Research (IJSR) \\ ISSN (Online): 2319-7064 \\ Index Copernicus Value (2015): 78.96 | Impact Factor (2015): 6.391}

resistance changes where it is depends on the particles movement. Figure 1(b) shows the movement of the particles for different shapes including normal, compressing and stretching. Before the force is applied, the shape of particle is normal and the resistance value is constant. Applying the force downward will cause the stretching where position of the graphite particles to be distant from one another, as a result the value of resistance will increase. Meanwhile, applying the force upward will compress the position of graphite particles and make is to be close to each other, which decrease the resistance value. In conclusion, the number of connected particles depends on the change of movement. The size of draw graphite is fixed for two types of pencils $2 \mathrm{~B}$ and $4 \mathrm{~B}$ as shown in Figure 2.
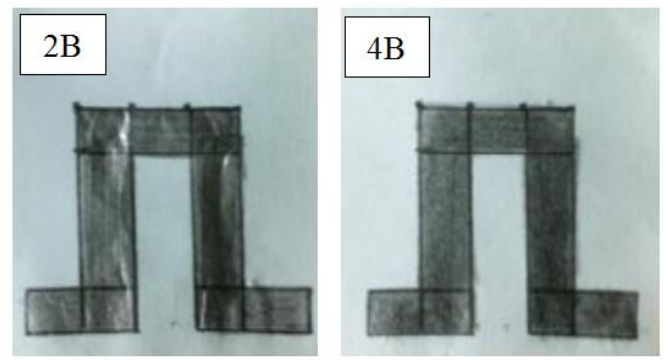

Figure 2: The same pattern is used for both $2 \mathrm{~B}$ and $4 \mathrm{~B}$ pencil

\section{Result and Discussion}

\subsection{Preliminary Test}

For a measurement, a sensor is connected to the digital multimeter with the help of wires and crocodile clips. For the preliminary test, the deflection is applied and resistance is recorded. As expected, two types of pencil grades give different output. The deflection is measured downward from the positive $\mathrm{x}$-axis starting $0.5 \mathrm{~cm}$ to $2.5 \mathrm{~cm}$..

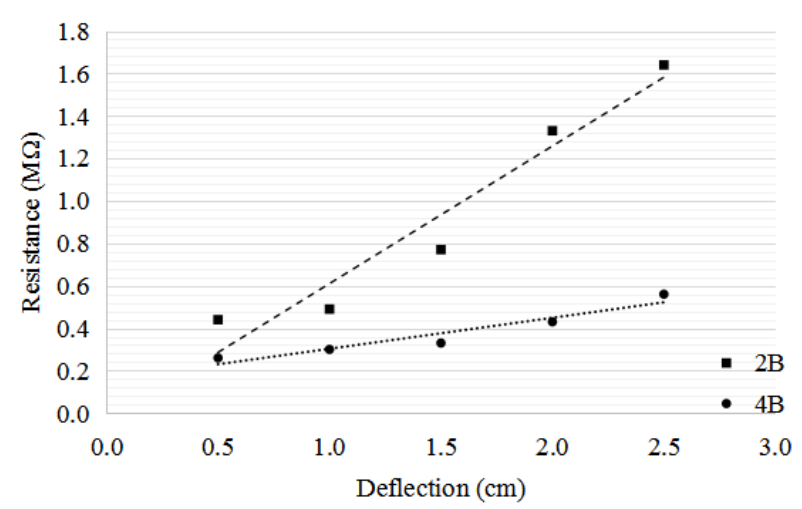

Figure 3: Deflection-Resistance change for 2B and 4B pencils.

The measured resistance of the sensor varies from $0.44 \mathrm{M} \Omega$ to $1.64 \mathrm{M} \Omega$ for $2 \mathrm{~B}$ pencil, and from $0.24 \mathrm{M} \Omega$ to $0.55 \mathrm{M} \Omega$ for $4 \mathrm{~B}$ pencil. The linear fit for $2 \mathrm{~B}$ pencil in equation (4) and $4 \mathrm{~B}$ pencil in equation (5) are obtained

$$
\begin{aligned}
& y=0.648 x-0.038 \\
& y=0.146 x+0.157
\end{aligned}
$$

The regression $R^{2}$ values for 2B pencil and 4B pencil were 0.9345 and 0.9169 respectively. This implies that the experimental data was close to a linear fit. The sensitivity of the sensor obtained was about $0.65 \mathrm{M} \Omega / \mathrm{cm}$ for $2 \mathrm{~B}$ pencil and $0.15 \mathrm{M} \Omega / \mathrm{cm}$ for $4 \mathrm{~B}$ pencil. Therefore, the $2 \mathrm{~B}$ pencil types is selected and suitable to be used for next experiment.

\subsection{Sensor Application}

In this work, the application is focused on the pressure measurement by using latex membrane. The developed pencil-on-paper strain sensor is attached to the membrane as shown in Figure 4.

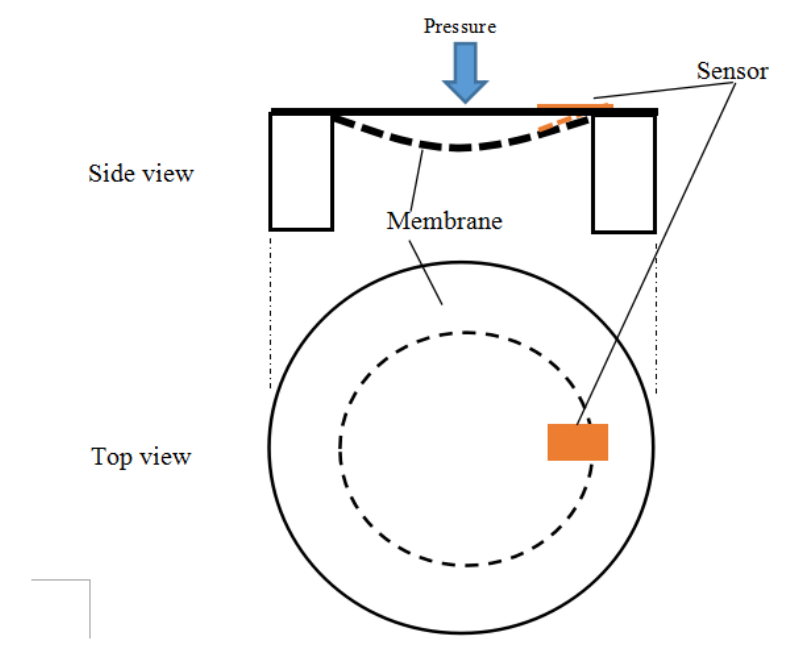

Figure 4: The experiment setup for sensor application

The pressure is applied to the membrane and it will deflect the membrane and sensor. Given the relationship between pressure, $P$ surface area, $A$ and force, $F$

$$
\begin{gathered}
P=\frac{F}{A} \\
W=\frac{3}{16} \frac{R^{4}}{t^{3}}\left(\frac{1-v^{2}}{E}\right) P
\end{gathered}
$$

where $R, t, v$ and $E$ are the radius, thickness of membrane, poisson's ratio and elastic modulus. In this case, the membrane deflection is depends on the applied pressure where the membrane deflection is measured by using pencilon-paper strain sensor. For the first case, the pressure is varied from 0 to $12 \mathrm{kPa}$ and surface area is fixed to $11.2 \mathrm{~cm}^{2}$. As shown in Figure 5, the resistance change $\Delta R$ is increase as the pressure increase. Means, the membrane deflection is proportional to the applied pressure. 


\section{International Journal of Science and Research (IJSR) \\ ISSN (Online): 2319-7064}

Index Copernicus Value (2015): 78.96 | Impact Factor (2015): 6.391

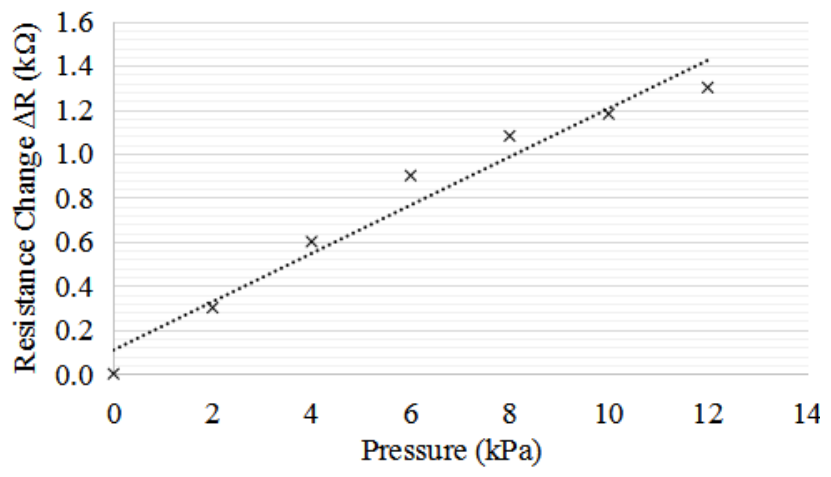

Figure 5: The resistance change for applied pressure

Then, the comparison using two different surface area are made for area $1\left(11.2 \mathrm{~cm}^{2}\right)$ and area $2\left(17.0 \mathrm{~cm}^{2}\right)$. The graph in Figure 6 shows the relation between applied force and surface area. As we can see, the large area that is area 2 give low resistance change compared to area 1 , it is prove that the large area will reduce the pressure acting on the membrane.

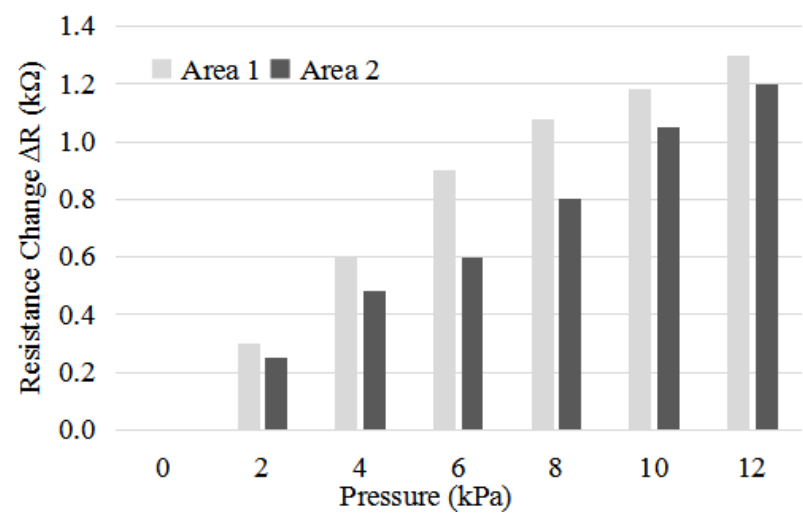

Figure 6: The resistanc change for different surface area

\section{Conclusion}

The simple strain sensor has been successfully developed using pencil and paper. The graphite of pencil is used to convert the strain into resistance changes. $2 \mathrm{~B}$ pencil was chosen based on its sensitivity compared to $4 \mathrm{~B}$ pencil. The applied pressure using different surface area may give the difference output response where large surface area reducing the resistance change.

\section{Future Work}

In future work, this sensor will be test for various types of applications such as monitoring pressure distribution for vehicle and air flow inside the tunnel.

\section{Acknowledgments}

This research is supported by University Research Grant UPSI (2016-0180-101-01). The authors would like to thank all staffs of the department of physics, Faculty of Science and Mathematics UPSI for assistance throughout the work.

\section{References}

[1] S. Ostman, "Detecting Chemicals, Measuring Strain with a Pencil and Paper", Northwestern University, 2014.

[2] H. Liu and R.M. Crooks. "Paper-based electrochemical sensing platform with integral battery and electrochromic read-out". Analytical Chemistry. Vol. 84, pp. 2528- 2532, 2012.

[3] Hoang-Phuang Phan, Dzung Viet Dao, Toan Dinh, Harrison Brooke, Afzaal Qamar, Nam-Trung Nguyen, Yong Zhu. "Graphite-On-Paper Based Tactile Sensors Using Plastic Laminating Technique, Proceedings of the IEEE International conference on Micro Electro Mechanical Systems (MEMS), 2015.

[4] Cheng-Wei Lin, Zhibo Zhao, Jaemyung Kim \& Jiaxing Huang. "Pencil Drawn Strain Gauges and Chemiresistors On Paper", Department of Materials Science and Engineering, Northwestern University, 2014

[5] Ting Kuo-Kang. "Tunable piezoresistive sensors based on pencil-on-paper", Applied Physics Letter. 104, 2014.

[6] J. E. Thompson. "Pencil-on-Paper Capacitors for HandDrawn RC Circuits and Capacitive Sensing", Journal of Chemistry, 2017.

[7] S. Timoshenko and S. Woinosky-Krieger. "Theory of Plates and Shell. New York, NY, USA: McGraw-Hill, 1987. 